\title{
Profiles of Cognitive Flexibility in Arithmetic Reasoning: A Cross- Country Comparison of German and American Elementary Students
}

\author{
Elisabeth Rathgeb-Schnierer \\ University of Kassel, Germany \\ Michael Green \\ University of North Carolina Charlotte, USA
}

Flexibility in performing mental calculations has become an important topic for research in mathematics education, resulting in a surge of research done in this field over the last two decades. While contemporary research shows the same basic idea of mental flexibility, different operational definitions and approaches have led to results that are not directly comparable. The study reported here focuses on cognitive flexibility in arithmetic reasoning in second and fourth grade German and American students, where flexibility is defined more intuitively by referring to students' knowledge and use of number patterns and relationships. Students were encouraged to sort 12 two-digit addition and subtraction problems reflecting a variety of number patterns into "easy" and "hard" groups and explain their reasoning. Qualitative results revealed a variety of reasoning patterns and profiles of flexibility and rigidity. Quantitative results indicated no country differences in cognitive flexibility and no grade differences for American students. However, German fourth graders exhibited significantly more flexible reasoning than German second graders.

Keywords: Cognitive flexibility, cognitive rigidity, mental arithmetic.

In recent decades, important research in mathematics education has been aimed at identifying and understanding students' techniques for performing mental addition and subtraction. In this context, students' ability to solve multi-digit arithmetic problems, without using paper and pencil computing algorithms, has come under increasing scrutiny among researchers (see e.g., Blőte, Klein, \& Beishuizen, 2000; Heirdsfield \& Cooper, 2004; Rathgeb-Schnierer, 2006; Threlfall, 2009).

At the beginning of the twenty-first century, the National Council of Teachers of Mathematics (NCTM) argued that students should be able to use a wide variety of problem solving strategies and that they should be able to adjust familiar strategies as well as invent new ones (NCTM, 2000). Critical to the effective use of mental strategies is cognitive flexibility, an attitude of mind that is both adaptive and agile. In this context, the past decade has seen significant 
gains in our understanding of mental processes that contribute to or make up mental flexibility (Grüßing, Schwabe, Heinze, \& Lipowsky, 2013; RathgebSchnierer \& Green, 2013; Selter, 2009; Threlfall, 2009). In addition, new approaches have been invented for conducting empirical research on mentally flexible strategies and procedures (Rathgeb-Schnierer \& Green, 2013, 2015; Threlfall, 2009; Torbeyns, De Smedt, Ghesquière, \& Verschaffel, 2009).

\section{Theoretical Background}

\section{Research Findings}

Contemporary research on cognitive flexibility in mental addition and subtraction has revealed several consistent patterns. For example, after learning the standard computing algorithms, students tend to prefer them and do not utilize previously learned strategies, even when the latter continue to be more advantageous and appropriate (Selter, 2000, 2001). Moreover, when students learn through examples, they tend to learn specific procedures rather than general rules or relationships, which in turn leads to a negative impact on the development of mental flexibility (Heirdsfield \& Cooper 2004; Klein, Beishuizen, \& Treffers, 1998; Schütte 2004). Others have reported that student strategies are related to the context of usage, as occurs with different target operations (Torbeyns et al., 2009), specific problem characteristics (Blöte et al., 2000; Torbeyns et al., 2009), and student-initiated recognition of problem characteristics (Rathgeb-Schnierer, 2006, 2010). Another pattern reported in the literature is that students who exhibit flexible and adaptive expertise in mental calculation also show deep understanding of number and operation relationships as well as knowledge of basic facts and fact families. These students also possess high self-confidence and a positive attitude towards mathematics (Heirdsfield \& Cooper, 2002, 2004; Threlfall, 2002). Additionally, they show recognition and use of number patterns and relationships to solve problems (Macintire \& Forrester 2003; Rathgeb-Schnierer 2006, 2010; Schütte 2004; Threlfall, 2009).

Pedagogically, the development of flexibility in mental calculation can be improved by special approaches to mathematics education. In this regard researchers have highlighted the problem-solving approach in general (Heinze, Marschick, \& Lipowsky, 2009; Heinze, Schwabe, Grüßing, \& Lipowski, 2015) combined with specific activities for fostering number sense and metacognitive competencies (this special approach is called "Zahlenblickschulung") (Rathgeb-Schnierer, 2006, 2010; Rechtsteiner-Merz, 2013). Furthermore, students with low achievement in mathematics need special instructional approaches to develop flexibility in mental calculation (Verschaffel, Torbeyns, De Smedt, Luwel, \& van Dooren, 2007). The approach termed "Zahlenblickschulung" supports the development of numerical relationships and conceptual knowledge in all students, including low achievers, which is the fundamental condition for developing calculation strategies and flexible mental 
calculation (Rechtsteiner-Merz, 2013). Finally, it is important to note that recent research in the field of flexible mental calculation reflects different interests and aims, and these in turn influence both the research methods and the data interpretation.

\section{Definitions of Flexibility}

In the current literature, there exist multiple and inconsistent definitions of mental flexibility, and these in turn have resulted in vastly different operational definitions (Star \& Newton 2009). For example, Star and Newton (2009) define flexibility as "knowledge of multiple solutions as well as the ability and tendency to selectively choose the most appropriate ones for a given problem” (p. 558). In a similar vein, Verschaffel, Luwel, Torbeyns, and Van Dooren (2009) prefer a distinction between "flexibility," to describe the use of multiple strategies, and "adaptivity," for the actual selection of appropriate strategy choices. In this vein, Selter (2009) extended the idea of "adaptivity" to creatively develop and select for use an "appropriate strategy." In marked contrast, another group of researchers has contended that flexibility consists of choosing among different strategies simply on the basis of the characteristics “... wherein strategy flexibility is conceived as selecting the strategy that brings the child most quickly to an accurate answer to the problem" (Torbeyns et al., 2009, p. 583).

There exists some consensus among all these definitions in the idea that flexibility in mental calculation includes two central features: the knowledge of different solution methods and the ability to adapt them appropriately when solving a problem. However, it is exactly in this respect that crucial differences in the definitions emerge. Threlfall (2009), for example, has identified two different explanatory models for flexibility in mental calculation: one based on the idea of conscious or unconscious strategic choice and one based on the idea of "zeroing in" on a solution based on number knowledge and conceptual understanding. Furthermore, Rechtsteiner-Merz (2013) has systematically analyzed the various notions of flexibility found in the literature and identified three different approaches regarding what exactly is meant by the adaptive use of strategies and how this can be identified: "(1) appropriateness of solution path and task characteristic, (2) appropriateness of correctness and speed, and (3) appropriateness of cognitive elements that sustain the solution process" (Nunes, Dorneles Vargas, Lin, \& Rathgeb-Schnierer, 2016, p. 13).

\section{Aims and Questions}

In contrast to the research summarized above, the project reported here did not focus on solving addition and subtraction problems. Rather, the emphasis here was on examining mental processes that underlie problem solving in terms of cognitive elements. In that context, the method used here examined directly whether students recognized problem characteristics, number patterns, and number relationships, and whether or not they used this knowledge 
for solving a problem (Rathgeb-Schnierer \& Green, 2013, 2015). This definition of flexibility differentiates between solution processes based on learned procedures (step-by-step mental calculations) versus recognized problem characteristics such as number patterns and numerical relationships. In this context, flexibility was viewed as a continuous, bi-polar construct, with rigidity at one extreme and flexibility at the other. Such a construct allowed measurement of the degree of flexibility students exhibited in a situation that demanded mental arithmetic.

Generally, the study was aimed at answering the following empirical questions:

- Is the flexibility/rigidity concept better characterized as continuous or bimodal?

- To what extent is cognitive flexibility in mental calculation related to sorting and reasoning patterns?

- Do students of different grade levels or countries exhibit differences in sorting and reasoning and in degrees of flexibility?

These research questions required the design of a new methodology since existing models do not generate relevant data for examining cognitive flexibility and rigidity (Rathgeb-Schnierer \& Green, 2017).

\section{Method}

\section{Sample}

The cross-country comparison required students from countries with different school systems and approaches to mathematics education. In Germany, there is a great emphasis on mental calculation (Krauthausen, 1993) in the elementary grades, with the standard computing algorithms for addition and subtraction introduced in the middle of third grade with three-digit numbers. In the United States, the standard addition algorithm is introduced in first grade, as soon as students are engaged with adding two-digit numbers. Based on this important cultural difference and results from former research (Selter, 2000), it was expected that second graders would be more flexible than fourth graders, and that German students would be more flexible than American students.

Sixty-nine elementary students were interviewed, all high and middle achievers selected by their teachers. These students were selected because pilot testing indicated that low achievers tended to be exclusively rigid in their thinking and nearly always failed to exhibit the flexibility strategies under investigation. The German sample consisted of 19 second graders and 11 fourth graders. The American sample was comprised of 22 second graders and 17 fourth graders. American students attended school in Charlotte, North Carolina, and German students were schooled in Baden-Württemberg. Students came from ten different classrooms (three second grade and two fourth grade classrooms in each country). 


\section{Problem Sorting}

Twelve problems were printed on $3 \times 5$ inch cards and arrayed randomly on a desk in front of the student. Students were asked to examine all the cards and place them, one at a time, over to the side labeled "Easy" or to the side labeled "Hard." Each problem was designed to show one or more of the following special features:

- 33+33: no regrouping, double digits; double facts at the ones place; inverse of 66-33

- 34+36: regrouping; double facts at the tens place; ones add up to ten

- 47+28: regrouping

- 56+29: regrouping; 29 close to thirty

- 65+35: regrouping; fives at the ones place add up to ten

- 73+26: no regrouping

- 31-29: renaming; range of numbers; 29 is close to thirty

- 46-19: renaming; 19 is close to twenty

- 63-25: renaming

- 66-33: no renaming; double and half relation; double digits; inverse of $33+33$

- 88-34: no renaming; double and half relation of the ones

- 95-15: no renaming; fives at the ones place

\section{Interviews}

Semi-structured interviews were developed to elicit students' reasoning for sorting problems as "easy" or "hard." After sorting a card, students were asked, "Why is this problem easy/hard for you?" The sequence of questions depended on the order in which students conducted their free sort of the 12 available cards. Each interview was comprised of two segments: (1) sorting problems into categories "easy" and "hard" and talking about the reasons for sorting, and (2) talking about how problems were solved. If it was indicated by the situation (for instance by utterance or action of the student), a third segment was sometimes added to compare selected problems by directing a student's attention to the characteristics of the problem (e.g., for 46-19, "Is there a way to make this problem easier?"). Occasionally a student was allowed to sort a card into an intermediate category midway between "easy" and "hard" (e.g., "This one is sorta easy and sorta hard"). Interviews lasted 15 to 30 minutes and were video recorded, conducted in students' native language, and transcribed for data analysis. 


\section{Data Analyses}

For data analysis, we employed a mixed approach using both qualitative and quantitative methods. In order to identify patterns in sorting and reasoning, we first undertook qualitative content analyses. Therefore, all interviews were transcribed in their original language. Based on theory and student data, a coding system was developed. Examination of student interviews suggested two types of underlying reasoning that were applied to both "easy" and "hard" problems. One type involved reasoning by problem characteristics (coded RCE and RCH for easy/hard sorting respectively). The second type incorporated reasoning by solution procedures (coded RSE and RSH for easy/hard sorting respectively). Both types led to distinct core categories that included several codes (see Figure 1) and sub-codes. The manual for coding is too detailed to be included here ${ }^{1}$. Reasoning by problem characteristics was coded when students referred specifically to problem characteristics (e.g. number patterns and numerical relationships such as proximity of 29 to 30 or double and half of 33 and 66). Reasoning by solution procedures was coded when students described any technique of mental, step-by-step computation.

\begin{tabular}{|l|l|}
\hline $\begin{array}{l}\text { Codes for RC } \\
\text { (analog for easy and hard) }\end{array}$ & $\begin{array}{l}\text { Codes for RS } \\
\text { (analog for easy and hard) }\end{array}$ \\
\hline relation of numbers & counting \\
\hline relation of tasks & find the difference \\
\hline analogies & compose and decompose \\
\hline features of ones & modify \\
\hline special numbers & standard algorithm \\
\hline size of numbers & other strategies \\
\hline basic facts & \\
\hline
\end{tabular}

Figure 1. Codes for reasoning by characteristic $(R C)$ and solution procedure (RS).

The complete data was independently coded by two trained judges using event sampling ${ }^{2}$. First, the whole data was segmented into events (with a precise definition of an event and 98\% agreement), and then the events were assigned to categories and codes. Each event was exclusively assigned to one of the four core categories. Therefore, the very first statement was used as indicator (no rater disagreements occurred on this assignment). In the same category, multiple codes could be allocated to an individual event. The coding for all data followed the procedure of consensual validation found in Padgett (2008). Figure 2 exemplifies two coding decisions.

\footnotetext{
${ }^{1}$ Contact lead author for detailed coding manual.

${ }^{2}$ For data coding and qualitative analyses, the software MAXQDA was used.
} 
Qualitative analyses provided crucial empirical evidence for subsequent quantitative analyses in which we sought to determine frequencies and distributions of flexible strategies as well as examine country and grade patterns in the data. Quantitative methods included descriptive statistics and hypothesis testing using analysis of variance.

\begin{tabular}{|l|l|}
\hline Reasoning $(\mathbf{3 3 + 3 3 )}$ & Coding \\
\hline $\begin{array}{l}\text { Its easy (moves } 33+33 \text { to the easy side) because it is } \\
\text { more of like a double fact so you would know it. }\end{array}$ & $\begin{array}{l}\text { reasoning by characteristic - easy } \\
\text { (core category) } \\
\text { relation of numbers (code) } \\
\text { double / half (sub-code) }\end{array}$ \\
$\begin{array}{l}\text { This one is easy (points on } 33+33) \text { because } 30 \text { plus } 30 \\
\text { equals } 60 \text {, and then plus } 3 \text { and plus } 3 .\end{array}$ & $\begin{array}{l}\text { reasoning by solution procedure - easy } \\
\text { (core category) } \\
\text { compose and decompose (code) }\end{array}$ \\
\hline
\end{tabular}

Figure 2. Examples of coding decisions.

\section{Results}

Qualitative analyses showed specific patterns in sorting and reasoning that led to identification of prototypes and revealed indicators of flexibility in mental arithmetic. Quantitative analysis provided interesting and unexpected evidence about country and grade patterns of arithmetic reasoning.

\section{Patterns in Sorting and Reasoning}

A total of 902 reasons were given by the sample (mean $=13.07$, minimum $=8$, maximum $=17$ ); $28.6 \%$ of the problems were judged as hard, $71.4 \%$ as easy. For the main categories, $54.5 \%$ were coded as reasoning by problem characteristics, $31.5 \%$ as reasoning by solution procedure ( $14 \%$ coded as "other" reasons were excluded from further data analyses).

A primary research interest was the extent to which students exhibited reasoning by problem characteristics. Figure 3 shows that frequency data.

\begin{tabular}{|c|c|c|c|c|c|}
\hline & $\mathbf{R C}$ & RCE & & RCH & \\
\hline codes & 492 & 351 & & 141 & \\
\hline relation of numbers & 47 & 47 & \multirow{3}{*}{$\begin{array}{l}\text { numerical } \\
\text { - relations } \\
\text { RNR (126) }\end{array}$} & 0 & \multirow{3}{*}{$\begin{array}{l}\text { numerical } \\
\text { relations } \\
\text { RNR (4) }\end{array}$} \\
\hline relation of tasks & 51 & 48 & & 3 & \\
\hline analogies & 32 & 31 & & 1 & \\
\hline features of ones & 178 & 57 & \multirow{3}{*}{$\begin{array}{l}\text { number } \\
\text { features } \\
\text { RNF (143) }\end{array}$} & 119 & \multirow{3}{*}{$\begin{array}{l}\text { number } \\
\text { features } \\
\text { RNF }(130)\end{array}$} \\
\hline special numbers & 84 & 79 & & 5 & \\
\hline size of numbers & 13 & 7 & & 6 & \\
\hline basic facts & 89 & 82 & & 7 & \\
\hline
\end{tabular}

Figure 3. Reasoning by problem characteristics. 
For sorting easy problems, student reasoning referred to numerical relations (RNR: 35.9\%), number features (RNF: 40.7\%), and basic facts (23.4\%). Reasoning by numerical relations comprised relation of numbers (e.g. range of numbers, double half, sum of ten), relation of tasks (e.g. inverse problems, commutativity, related problems) and analogies of tens and ones. Reasoning by number features included special features of the ones (e.g. sum of ten, no regrouping or renaming needed), special numbers (e.g. double digits, numbers close to the next ten) or the size of numbers. Reasoning by basic facts contained a statement that parts of a problem or a whole problem was known by rote memorization; naming of a result was not coded as a basic fact reason.

A completely different pattern occurred in the core category reasoning by problem characteristics for hard problems. For problems sorted this way, students referred predominantly to number features and argued based on the features of the numbers at the ones place (84.4\%). As Figure 4 illustrates, the need to rename for subtraction problems was often sufficient for students to label it "hard," while those who noticed other number features just as typically reported the same problem to be "easy."

\section{RCH: $31-29$}

This (puts 31 - 29 to the "hard" column) is a little harder because you can't take 9 away from 1 so you have to regroup.

\section{RCE: $31-29$}

This is an easy one (31-29) cause both of the numbers are very close to each other so - ahm you can find out that there're only a couple numbers apart, and so the answer would be two.

Figure 4. Examples of reasoning for 31-29.

\section{Varieties of Reasoning}

Regarding the variety of reasoning exhibited by our students for easy problems, different patterns in the core categories emerged for reasoning by problem characteristics (RCE) and reasoning by solution procedures (RSE). In Figure 5, each column represents a student's reasoning for easy problems. Squares differed in size to reflect relative frequency (large $=$ more reasons) of reasons assigned to a code (left column). Figure 5 illustrates all 69 students and shows two distinct patterns regarding reasoning by problem characteristics (RCE) and reasoning by solution procedures (RSE).

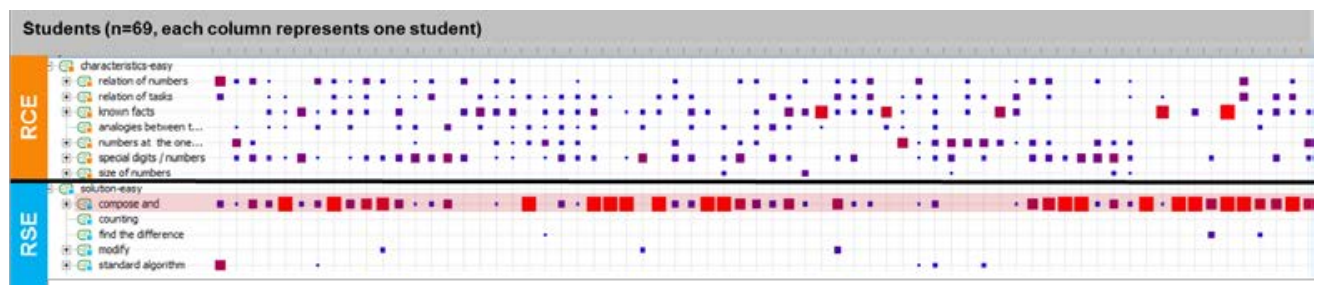

Figure 5. Profiles of reasoning for easy problems.

The distribution of squares in the top part of Figure 5 (category RCE) shows that students who reasoned by problem characteristics (orange section) 
tended to produce a much greater variety of reasons than students who reasoned by solution procedure (blue section). Note, for example, in the category RSE (bottom part of Figure 5) the squares are predominantly located in one line, indicating that these students tended to refer to only one reason (always involving composing and decomposing) that applies across all problems.

\section{Profiles of Reasoning}

In terms of students' reasoning about easy and hard problems, three profiles were identified, as shown graphically in Figure 6.

\begin{tabular}{|c|c|c|}
\hline & P1 & P3 \\
\hline
\end{tabular}

Figure 6. Students' profiles of reasoning.

Profile one ( $\mathrm{P} 1, \mathrm{n}=21$ students) can be characterized by a reasoning pattern that showed a clear preference for reasoning by problem characteristics. Students who exemplified this profile showed more than $75 \%$ of their reasons referred to problem characteristics. Typically, their reasoning was marked by a great variety of reasons, and each reason matched special features of the given problem. Profile two (P2, n = 6 students) can be characterized by a distinct preference for reasoning by solution procedures. Students who belonged to this profile exhibited a quite restricted range in their reasoning. Students who based reasoning on solution procedures consistently described "composing and decomposing" of numbers and number combinations. When reasoning was based on problem characteristics, these students referred predominantly to "memorized basic facts." Profile three (P3, n = 42 students) can be characterized by mixed reasoning, with either more emphasis on problem characteristics (type a, 25 students) or on solution procedures (type b, 14 students) or equally balanced (3 students). Students in this profile can be described as more comprehensive, since problem-based and procedure-based reasons can coexist. When the mixed group reasoned about number patterns or relationships, they used a variety of reasoning, but when they reasoned about solution procedures, their thinking was strictly rigid.

Qualitative analysis uncovered two additional patterns. First, whenever students referred to problem characteristics or to number patterns, their reasoning exhibited cognitive flexibility. These students exemplified our thinking about cognitive flexibility. Second, whenever students exhibited reasoning based on solution procedures, they gave a restricted range of reasons. These students acted very statically, with a single reason for very different problems. Their profile is the hallmark of mental rigidity.

Based on our theoretical orientation and the qualitative findings reported here, we operationally defined mental flexibility as any reasoning by 
problem characteristics (RC). In contrast, reasons coded "reasoning by solution procedure" (RS) were classified as "rigid" (with the exception of one sub-code in the category, "reasoning by solution procedure," which represented less than one percent of coded responses).

\section{Quantitative Results}

To examine more generally patterns of students' flexible reasoning, we distinguished between the frequency of flexible reasons (see Table 1) and the repertoire of flexible reasons (see Table 2). Such a distinction is important because some students may exhibit a high frequency but limited range of flexible reasons.

Regarding the frequency, some students provided multiple, flexible reasons for their sorting; others provided none. Within the sample, sorting reasons coded as flexible ranged from 0 to 17 , with a mean of 7.20 and a standard deviation of 4.09. Plotted as a histogram, the data clearly reflected a continuous distribution across all possible values between the two extremes $(0$, 17); more individuals were clustered toward the center of the distribution than toward its extremes. Mean group frequencies of flexible reasoning exhibited by our sample are shown in Table 1.

A significant country-by-grade interaction was found for frequency of flexibility reasoning $(F(1,65)=5.53, p=.022)$. In addition, a significant effect was found for grade $(F(1,65)=6.20, p=.015)$, with fourth graders producing significantly more flexible reasons than second graders. No country difference was found $(F(1,65)=2.46, p=.121)$.

Table 1

Frequency of Flexible Reasoning (RC) by Country and Grade for 12 Problems

\begin{tabular}{ccccc}
\hline & & 2nd Grade & 4th Grade & Total \\
\hline \multirow{2}{*}{$\begin{array}{c}\text { American } \\
\text { Students }\end{array}$} & Mean & 8.05 & 8.18 & 8.10 \\
\cline { 2 - 5 } & SD & 3.56 & 3.19 & 3.54 \\
\cline { 2 - 5 } & $\mathrm{n}$ & 22 & 17 & 39 \\
\hline \multirow{2}{*}{ German } & Mean & 4.37 & 8.91 & 6.03 \\
\cline { 2 - 5 } Students & SD & 3.06 & 5.28 & 4.51 \\
\cline { 2 - 5 } & $\mathrm{n}$ & 19 & 11 & 30 \\
\hline \multirow{2}{*}{$\begin{array}{c}\text { Column } \\
\text { Total }\end{array}$} & Mean & 6.34 & 8.46 & 7.20 \\
\cline { 2 - 5 } & SD & 3.94 & 4,06 & 4.09 \\
\cline { 2 - 5 } & $\mathrm{n}$ & 41 & 28 & 69 \\
\hline
\end{tabular}

Regarding the repertoire or range of flexible reasons (see Table 2), individual repertoires ranged from only 0 to 11 . Plotted as a histogram, the data clearly reflected a continuous distribution across all possible values between 
the two extremes $(0,11)$. As with frequencies, more individuals were clustered toward the center of the distribution than toward its extremes.

Table 2

\section{Repertoire of Flexible Reasons by County and Grade for 12 Problems}

\begin{tabular}{ccccc}
\hline & & 2nd Grade & 4th Grade & Total \\
\hline \multirow{2}{*}{$\begin{array}{c}\text { American } \\
\text { Students }\end{array}$} & Mean & 4.91 & 5.47 & 5.15 \\
\cline { 2 - 5 } & SD & 1.90 & 1.28 & 1.66 \\
\cline { 2 - 5 } & $\mathrm{n}$ & 22 & 17 & 39 \\
\hline \multirow{2}{*}{ German } & Mean & 3.21 & 6.18 & 4.30 \\
\cline { 2 - 5 } Students & SD & 2.29 & 3.48 & 3.09 \\
\cline { 2 - 5 } & $\mathrm{n}$ & 19 & 11 & 30 \\
\hline \multirow{2}{*}{$\begin{array}{c}\text { Column } \\
\text { Total }\end{array}$} & Mean & 4.12 & 5.75 & 4.78 \\
\cline { 2 - 5 } & $\mathrm{SD}$ & 2.23 & 2.36 & 2.41 \\
\cline { 2 - 5 } & $\mathrm{n}$ & 41 & 28 & 69 \\
\hline
\end{tabular}

The findings regarding the repertoire offer an important check on the results reported for frequency of flexible reasoning. A significant country-bygrade interaction was found for the repertoire of flexible reasons $(F(1,65)=$ $4.77, p=.032$ ) and may be the primary factor at play in the significant effect found for grade $(F(1,65)=10.26, p=.002)$. No country difference was found $(F(1,65)=.802, p=.374)$.

A two-factor MANOVA was used to examine country and grade effects on three other dependent variables (no interaction effects found) identified in the qualitative analysis:

- Reasoning by Solution Procedures (not significant for country and grade)

- Problem Characteristics - Reasoning by Number Features (not significant for country and grade)

- Problem Characteristics - Reasoning by Number Relationships (significant for grade $-F(1,65)=9.24, p=.003, d=.85$ )

\section{Discussion and Conclusion}

The results presented in this report suggest sufficiently compelling answers to the research questions to warrant further investigation. Concerning mental flexibility in sorting addition and subtraction problems, the empirical data clearly indicated that mental flexibility was best characterized as continuous rather than bimodal: $30.4 \%$ of the students could be described as extremely flexible (P1), only few (8.7\%) could be described as extremely rigid 
(P2). The majority (60.9\%) displayed some mixture of both rigid and flexible reasoning (P3).

Our data also show that the sorting and reasoning patterns identified earlier are empirically useful indicators of cognitive flexibility in mental arithmetic. Whenever students relied on number characteristics and numerical relations, they exhibited not only a variety of reasons, but also reasons that were well adapted to individual problems. In our view, students' use of number patterns and relationships provides a more differentiated and appropriate way to define and operationalize flexibility in mental arithmetic than alternative approaches that employ elapsed time and solution accuracy (cf. Star \& Newton, 2009; Torbyns et al., 2009; Verschaffel et al., 2009).

Our statistical results on frequency and repertoire of flexible reasons showed both a significant country-by-grade interaction effect for mental flexibility and a main effect for grade across countries, with fourth graders exhibiting more mental flexibility than second graders. In our opinion, it appears most likely that the grade difference was due to the country-by-grade interaction. That is, there was virtually no difference between second and fourth grade American students. In contrast, German fourth graders generated nearly double the flexible reasons in comparison to German second graders.

This last finding is intriguing for us. While specific variation does occur, there is a general mathematics sequence in American elementary schools in which the computing algorithms for each operation are introduced sequentially, grade-by-grade: first grade - addition, second grade - subtraction, third grade - multiplication, fourth grade - division. In contrast, German states typically introduce number reasoning in the primary grades and reserve computing algorithms for higher grades. Given these geographic differences, our own teaching and school experiences, and former research (Selter, 2000), we had expected that German fourth graders would exhibit more solution procedure types of reasoning (rigid) than German second graders. Yet, the opposite was found in our data. German fourth graders exhibited significantly greater flexibility than German second graders. This result can possibly be explained by two aspects: the set of problems and the specific approach to reveal flexibility.

(1) Set of problems: We used the same set of problems with two-digit numbers for second and fourth graders. Since the fourth graders are more familiar with two-digit numbers, this could explain why they exhibited more flexibility. But, if this had been the crucial reason, we would have expected a greater grade-level difference in the American sample. In contrast to the research reported by Selter (2000), the different set of problems (Selter used three-digit problems) could be responsible for different results.

(2) Approach: Selter (2000) has reported that students act less flexible in solving problems after they have learned the standard procedures 
in third grade. Our approach asked students to sort rather than to solve problems. It might be that the request to solve a problem leads to the immediate use of a procedure that might not be appropriate for the problem, even if the students were able to recognize task characteristics and numerical relations and to adapt appropriate strategies. If the task of sorting versus the task of solving influenced students' reaction, this could be another explanation for the differences in the results.

The discrepancy between Selter's (2000) results for fourth grade students and those reported here needs additional study. Our results call into question the popularly held belief that German students abandon flexible mathematics strategies once they learn standard computing algorithms. Moreover, implied in this study is the need to assess the extent to which profiles of cognitive flexibility reported here can be replicated with the arithmetic operations of multiplication and division.

Nearly two decades ago, NCTM (2000) called for an increase in emphasis on developing in students a deep, rich variety of problem solving strategies. The data from this study clearly showed that students as young as second grade exhibited a variety of strategies, and they made appropriate selections among the strategies available to them. What still needs to be worked out by mathematics educators is the most effective pedagogical methods for instilling cognitive flexibility as a general "attitude of mind" and for teaching specific strategies in particular. At the present time, what is clear is that primary grade teachers should include frequent, real-world, problem-solving opportunities for flexible mental reasoning. For example, our data showed that cognitive flexibility was exhibited when students recognized problem characteristics, patterns, and numerical relations. Consequently, we would encourage mathematics educators to encourage student patience and reflection when faced with computational problems in order to stimulate available cognitive flexibility (Rechtsteiner-Merz \& Rathgeb-Schnierer, 2015).

\section{References}

Anghileri, J. (2001). Intuitive approaches, mental strategies and standard algorithms. In J. Anghileri (Ed.), Principles and practices in arithmetic teaching: Innovative approaches for the primary classroom (79-94). Suffolk, UK: St Edmundsbury Press.

Beishuizen, M., \& Klein, A. S. (1998). The empty number line in Dutch second grades: Realistic versus gradual program design. Journal for Research in Mathematics Education, 29(4), 443-464.

Blöte, A.W., Klein, A.S., \& Beishuizen, M. (2000). Mental computation and conceptual understanding. Learning and Instruction, 10(3), 221-247. 
Heinze, A., Marschick, F., \& Lipowsky, F. (2009). Addition and subtraction of three-digit numbers: Adaptive strategy use and the influence of instruction in German third grade. ZDM - The International Journal on Mathematics Education, 41(5), 591-604.

Grüßing, M., Schwabe, J., Heinze, A., \& Lipowsky, F. (2013). The effects of two instructional approaches on 3rd-graders' adaptive strategy use for multi-digit addition and subtraction. In A. M. Lindmeier \& A. Heinze (Eds.), Proceedings of the 37th Conference of the International Group for the Psychology of Mathematics Education (Vol. 2, 393-401). Kiel: PME.

Heinze, A., Schwabe, J., Grüßing, M., \& Lipowsky, F. (2015). Effects of instruction on strategy types chosen by German 3rd-graders for multi-digit addition and subtraction tasks: An experimental study. In K. Beswick, T. Muir, \& J. Wells (Eds.), Proceedings of the 39th Conference of the International Group for the Psychology of Mathematics Education (Vol. 3, 49-56). Hobart, Australia: PME.

Heirdsfield, A. M., \& Cooper, T. J. (2002). Flexibility and inflexibility in accurate mental addition and subtraction: Two case studies. Journal of Mathematical Behavior, 21(1), 57-74.

Heirdsfield, A.M., \& Cooper, T.J. (2004). Factors affecting the process of proficient mental addition and subtraction: Case studies of flexible and inflexible computers. Journal of Mathematical Behavior, 23(4), 443-463.

Krauthausen, G. (1993). Kopfrechnen, halbschriftliches Rechnen, schriftliche Normalverfahren, Taschenrechner: Für eine Neubestimmung des Stellenwertes der vier Rechenmethoden [Mental arithmetic, informal strategies, written algorithms, calculators. A new role of routine procedures]. Journal für Mathematik-Didaktik, 14(3/4), 189-219.

Macintyre, T., \& Forrester, R. (2003). Strategies for mental calculation. In J. Williams (Ed.), Proceedings of the British Society for Research into Learning Mathematics, 23(2), 49-54.

National Council of Teachers of Mathematics (NCTM) (2000). Principles and standards for school mathematics. Reston, VA: Author.

Nunes, T., Dorneles Vargas, B., Lin, P-J., \& Rathgeb-Schnierer, E. (2016). Teaching and learning about whole numbers in primary school. ICME-13. Topical Survey. Switzerland: Springer.

Padgett, D.K. (2008). Qualitative methods in social work research ( $2^{\text {nd }}$ Edition). Los Angeles; London; New York; Singapore: SAGE.

Rathgeb-Schnierer, E. (2006). Kinder auf dem Weg zum flexiblen Rechnen: Eine Untersuchung zur Entwicklung von Rechenwegen von Grundschulkindern auf der Grundlage offener Lernangebote und eigenständiger Lösungsansätze [Study on students' flexibility in mental calculation based on an open approach]. Hildesheim; Berlin: Franzbecker.

Rathgeb-Schnierer, E. (2010). Entwicklung flexibler Rechenkompetenzen bei Grundschulkindern des 2. Schuljahrs [The development of flexible 
mental calculations of second graders]. Journal für Mathematik-Didaktik, 31(2), 257-283.

Rathgeb-Schnierer, E., \& Green, M. (2013). Flexibility in mental calculation in elementary students from different math classes. In B. Ubuz, Ç. Haser, \& M. A. Mariotti (Eds.), Proceedings of the Eighth Congress of the European Society for Research in Mathematics Education (pp. 353-362). Ankara, Turkey: Middle East Technical University.

Rathgeb-Schnierer, E., \& Green, M. (2015). Cognitive flexibility and reasoning patterns in American and German elementary students when sorting addition and subtraction problems. In K. Krainer \& N. Vondrová (Eds.), CERME 9 - Ninth Congress of the European Society for Research in Mathematics Education (pp. 339-345). Prague, Czech Republic.

Rathgeb-Schnierer, E., \& Green, M. (2017). Mental arithmetic and cognitive flexibility in elementary students. Proceedings of the 11th annual International Technology, Education and Development Conference (pp. 492-499), Valencia, Spain: INTED.

Rechtsteiner-Merz, Ch. (2013). Flexibles Rechnen und Zahlenblickschulung. Entwicklung und Förderung von Rechenkompetenzen bei Erstklässlern, die Schwierigkeiten beim Rechnenlernen zeigen. [Flexible mental calculation and „Zahlenblickschulung“. Developing flexible mental calculation in low achieving first grade students] Münster: Waxmann.

Rechtsteiner-Merz, Ch., \& Rathgeb-Schnierer, E. (2015). Flexible mental calculation and Zahlenblickschulung“. K. Krainer, \& N. Vondrovà (Eds.), CERME9. Proceedings of the Ninth Congress of the European Society for Research in Mathematics Education (pp. 354-360). Prague, Czech Republic: Charles University.

Schütte, S. (2004). Rechenwegsnotation und Zahlenblick als Vehikel des Aufbaus flexibler Rechenkompetenzen [Notation of calculation processes and number sense as a vehicle to develop flexible arithmetic competencies]. Journal für Mathematik-Didaktik, 25(2), 130-148.

Selter, C. (2000). Vorgehensweise von Grundschüler(inne)n bei Aufgaben zur Addition und Subtraktion im Zahlenraum bis 1000 [Strategies of primary students in addition and subtraction of three-digit numbers]. Journal für Mathematik-Didaktik, 21(3/4), 227-258.

Selter, C. (2001). Addition and subtraction of three-digit numbers: German elementary children's success, methods and strategies. Educational Studies in Mathematics, 47(2), 145-173.

Selter, C. (2009). Creativity, flexibility, adaptivity, and strategy use in mathematics. ZDM - The International Journal on Mathematics Education, 41(5), 619-625.

Star, J. R., \& Newton, K. J. (2009). The nature and development of experts' strategy flexibility for solving equations. ZDM - The International Journal on Mathematics Education, 41(5), 557-567. 
Threlfall, J. (2002). Flexible mental calculation. Educational Studies in Mathematics, 50(1), 29-47.

Threlfall, J. (2009). Strategies and flexibility in mental calculation. ZDM - The International Journal on Mathematics Education, 41(5), 541-555.

Torbeyns, J., De Smedt, B., Ghesquière, P., \& Verschaffel, L. (2009). Jump or compensate? Strategy flexibility in the number domain up to 100. ZDM The International Journal on Mathematics Education, 41(5), 581-590.

Verschaffel, L., Torbeyns, J., De Smedt, B., \& Van Dooren, W. (2007). Strategy flexibility in children with low achievement in mathematics. Educational and Child Psychology, 24(2), 16-27.

Verschaffel, L., Luwel, K., Torbeyns, J., \& Van Dooren, W. (2009). Conceptualizing, investigating, and enhancing adaptive expertise in elementary mathematics education. European Journal of Psychology of Education, 24(3), 335-359.

\section{Authors:}

Elisabeth Rathgeb-Schnierer

University of Kassel, Germany

Email: rathgeb-schnierer@mathematik.uni-kassel.de

Michael Green

University of North Carolina, Charlotte, USA

Email:mggreen@uncc.edu 